\title{
SUSTAINABILITY AND THE OLYMPICS: THE CASE OF ATHENS 2004
}

\author{
G. TZIRALIS, A. TOLIS, I. TATSIOPOULOS \& K. ARAVOSSIS \\ Sector of Industrial Management and Operational Research, School of Mechanical Engineering, \\ National Technical University of Athens, Greece.
}

\begin{abstract}
While economy and ecology ought to share the same values and targets, as their common 'eco' prefix indicates, reality tends to be somehow different. Economic growth and environmental protection seem to be noncompatible, both in methods and in results. In many cases, for example, investments trigger actions that operate competitively to the wealth of the environment, while the strict application of environmental directives often results in halting development. Moreover, the tendency towards constant economic growth is a desirable and inherent characteristic of human nature, which is apparently not to be changed in the near future. In this context, the need for a bundle of approaches that could tie the objectives of economic growth and environmental protection, namely to maximize the total social wealth, arises as pressing and this need has finally led to the birth of the fields of sustainable development and environmental economics. As a result, the compatibility testing of each investment project with the standards and principles settled by sustainable development is a matter of concern. Following the call for sustainability, this paper is among the first to address both the economic and environmental impact of the biggest of events globally, the Olympics. Focusing on the Games of Athens 2004, the text describes a framework of Olympic impact assessment, in terms of properly shaped sustainable performance indicators. Data and facts concerning the total budget of the Games are presented, while the evolution of the Games' economic context is monitored through the volume of labour force, unemployment rate and energy consumption. The sustainability and environmental impact is also assessed, mainly through the areas of interest of transport networks and pollution, among others. Eventually, the paper demonstrates a holistic approach towards assessing the sustainable impact of the Olympic Games, in term of its implementation in the Athens 2004 case.
\end{abstract}

Keywords: Athens 2004 Olympic Games, economic impact, environment, Olympic Games Global Impact, sustainable development.

\section{INTRODUCTION}

\subsection{Growth versus environment}

Ecology and economy ought to push, in principle, in the same direction. The 'eco' part of each word stands for the ultimate evidence, as it derives from the Greek word 'home'. In full accordance, the proponents of both claim to have common welfare as their primary goal.

Reality, however, is confirmed to be somehow different. The relationship between economic growth and the environment is, and may always remain, controversial. Considering the inherent human tendency to constant economic development, the objectives of growth and environmental protection may arise as inconsistent. As Lucas [1] points out, 'Once one starts to think about [economic growth], it is hard to think about anything else.'

This relationship between economic growth and the environment has received much attention in the recent decades. According to the early work of some social and physical scientists, growing economic activity (production and consumption) requires larger inputs of energy and material, and generates larger quantities of waste by-products [2,3]. At the other extreme, some researchers argue that the fastest road to environmental improvement is along the path of economic growth: with higher incomes comes increased demand for goods and services that are less material intensive, as 
well as demand for improved environmental quality that leads to the adoption of environmental protection measures [4]. As Beckerman [5] puts it, 'The strong correlation between incomes, and the extent to which environmental protection measures are adopted, demonstrates that, in the longer run, the surest way to improve your environment is to become rich.'

The newer literature of 1990s focuses on the study of this link between economic growth and environmental quality. Panayotou [4] refers to numerous researchers, such as Grossman and Kreuger [6] and Selden and Song [7], who have hypothesized that this relationship-between economic growth and environmental quality-, whether positive or negative, is not fixed along a country's development path; indeed, it may change sign from positive to negative as a country reaches a level of income at which people demand and afford more efficient infrastructure and a cleaner environment. The implied inverted-U relationship between environmental degradation and economic growth came to be known as the 'environmental Kuznets curve', by analogy with the income inequality relationship postulated by Kuznets.

\subsection{Sustainable development}

After all, no matter to what extent it is finally understood or remains a hot research topic, the relationship between economic development and environmental protection does exist. Considering the ambiguity of its nature, the need for a framework that secures the relationships' elements compatibility arises as of vital importance. Growth and environmental protection could and should be in harmony in principles, methods and targets; this harmony is called sustainable development.

In 1987, the World Commission on Environment and Development defined sustainable economic development as 'development that meets the needs of the present without compromising the ability of future generations to meet their own needs' [8]. The United Nations responded thoroughly, in 1992, in this pressing need with Agenda 21, an extended list of guiding principles and modus operandi, reflecting a global consensus and political commitment at the highest level on development and environmental cooperation for the integration of environmental and development concerns [9].

The compatibility to the environmental protection framework for economic growth is therefore known and widely accepted. The matter that arises in a natural way regards the methods that may be used to assess the sustainability of economic development, whether it concerns the development of a region, enterprise or a project. According to the International Institute for Sustainable Development [10], it is necessary to identify the essential component systems and to define indicators that can provide essential and reliable information about the viability of each and of the total system. Such indicators, formed according to certain requirements [10,11], are able to provide comprehensive information about the systems shaping sustainable development.

To abbreviate, the pressing need for harmonizing economic growth with environmentalism is assured only by the notion of sustainability, which should determine the boundaries for every development plan and could be assessed through properly defined indicators.

\subsection{The Olympics}

The Olympic Games comprise the biggest of events that a city can organize. The size of the Olympic event and the activities needed for the preparation and hosting of the Games are on a scale capable of acting as a catalyst for urban redevelopment, enabling changes, which might normally take several decades to complete [12]. The growth and financial gigantism of the Games are today such that, for example, the overall impact of the Games of Sydney 2000 was to increase the whole Australian economic activity by $0.12 \%$ over a 12 -year period from 1994 [13]. As a direct result, 
the occurring investments and the reconstruction of the city pose a strong influence on the region's environment. The bundle of relevant issues is not covered sufficiently in the relevant Olympic bibliography, which is after all limited. However, the impact on the environment is considerably significant, in terms of raw materials used, energy consumption, water conservation, transport and contamination [14].

At long last, the size and extent of the economic and environmental issues that arise from hosting an Olympic event make the measurement of the sustainability of the project a subject of vital importance.

\subsection{Scope and contents}

This study aims aimed at recording, monitoring and assessing the sustainability impact of the Olympic Games of Athens 2004. The introduction section is followed by an analytical description of the methodology selected and used for assessment of the Games' sustainable impact in Section 2. Section 3 portrays the economic dimension of the Games, while Section 4 deals with environmental aspects. Section 5 summarizes the outcomes of the study, while also suggesting directions for further research.

\section{THE METHOD}

The International Olympic Committee (IOC) has recently responded to the urging and tempting need for identifying and measuring the impact of the Games in terms of their sustainability by introducing the Olympic Games Global Impact (OGGI) project. The Académie Internationale des Sciences et Techniques du Sport (AISTS) of Lausanne studied and finally created - on behalf of the IOC - a framework of analysis and a set of indicators for the identification of the sustainable impact of Olympics [15-18]. The fundamentals of this framework, which was created to capture in a consistent and comparable manner the impact of the Games, are described hereafter and in parallel illustrated in Fig. 1.

As an essential consideration, the Games' impact is defined as the interrelation between the Olympic event and its context of realization. Adopting this dual view, two clusters of indicators are

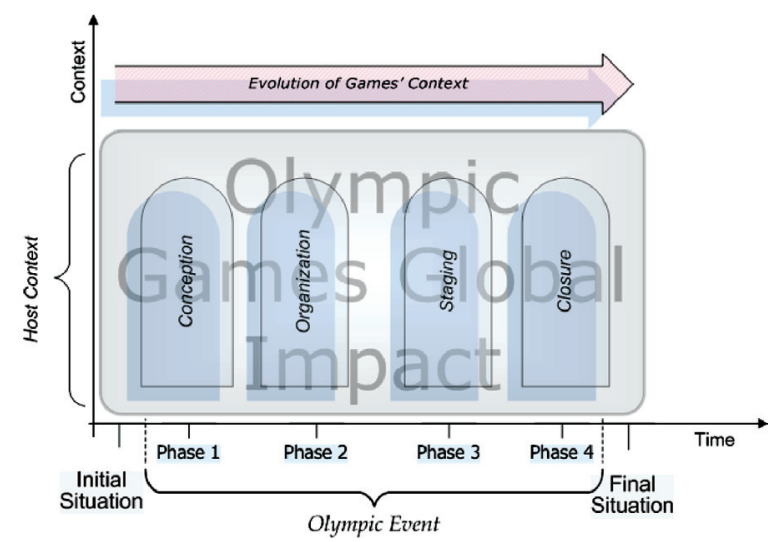

Figure 1: The Olympic Games Global Impact framework for the identification of the sustainable impact of the Olympics. 
introduced, one for monitoring the event and another for the depiction of its context. The global intrinsic impact arises ultimately circularly, as an area in which the complex interrelationship between the event and its context takes place. The mapping of the area, with the appropriate spatial, temporal and details coloration, is selected to be incarnated by use of appropriately selected and modulated indicators.

The first degree of freedom, which characterizes the set of indicators, is space. The proposed framework considers three different geographical entities in regional, national and global level. The second degree of freedom regards time. As temporal boundaries are picked, the official announcement of the city's candidacy (initial situation) and the completion of 2 years after the staging of the Games (final situation), are broken down in the phases of conception, organization, staging and closure.

The methodological framework outlines as relevant to the Olympic event two groups of activities. The first one, Olympic activities, includes the totality of activities that derive directly from the occurrence of the Olympic event, namely activities that were performed during the conception, development, use and post-Olympic conversion of areas and facilities specific to the Games, such as sports areas and Olympic villages. The second one regards activities that aim at supporting the first group of activities described above and complexity of the event infrastructure, such as transport networks.

The methodological framework results finally in a proposed set of 159 sustainable indicators and 1726 operational variables, congregating to the integrated assessment of the Olympic impact. For the needs of this study, a selected subset of these indicators, relevant and able to highlight the case of Athens, was worked out and the most updated data for them was collected, through an extensive search over the totality of relevant organizations and offices. The most influential and illustrative outcomes out of these indicators, regarding the spheres of the economy and the environment, are analysed hereafter to document and determine the sustainable impact of the Olympic Games of 2004.

\section{ECONOMIC SIZE AND IMPACT ON THE ECONOMICS OF THE CITY AND THE COUNTRY}

This section reports the main features of the economic dimension of Athens' Games. Adopting the approach of the OGGI framework, the economic sphere of the Games' impact is formed by both the event and its context of realization. The economic aspects of the Olympic event are covered briefly in this section, while the evolution of the Games' economic context is also discussed and possible associations between the event and its context's evolution are marked out. The sources for the raw data used for extracting the results referred to this section are the General Accounting Office and the National Statistics Office of Greece.

The total expenditure of the Olympic Games of Athens 2004, both operating and capital, regarding the Olympic, as well as the context activities, was finally equal to 11.274 billion euro. Only the $20.1 \%$ of this cost was finally covered by private funding, all the rest being public subsidy. The sustainability of the Games' impact could be further documented, except from the significant economic size of the Olympic event, by the permanent nature of the facilities used for staging the Games. Out of the 1.975 billion euro spent for the renovation or construction of Olympic facilities, only $10.2 \%$ concerned temporal facilities.

The following paragraphs attempt to show evidence on associating the preparation and staging of the Games with the economic development of the hosting region, namely the prefecture of Attica, or even the whole of Greece.

The triggering effect of the Games, as long as the stimulation of numerous activities whose connection with the Games is difficult to identify, could be made clear through the parallel 
consideration of principal economic indicators of the hosting region and the whole country. Those that point to the most indicative views of impact are mentioned in the following.

The volume of labour force stands definitely among them. The country's labour force expanded from 4.526 millions of employees in 1998 to 4.844 millions in 2005, namely an increase of $7.0 \%$. In contrast, during the same period, the labour force in Attica region ballooned from 1.596 to 1.784 millions of employees, an expansion of $11.8 \%$. This variation in extent could be ascribed to the Games, since the most part of the increase in Attica's labour force, namely 4.35\%, was monitored during the Games' year, as it is depicted in Fig. 2. In other words, the Games were the major reason for attracting an extra amount of labour force in Athens, an amount that remained in the region after the staging of the event. The question that arises unsurprisingly regards the employment rate.

The percentage of unemployed in both Greece and Attica prefecture were about 12\% in 1999. This percentage diminished successively in the following years till 2003. However, as Fig. 3 illustrates, the trend was more intense in Attica rather than in the whole country. As a result, the unemployment rate from 2003 to 2005 was $9 \%$ in the capital's region, while about $10 \%$ at national level. The Games was the major cause not only for the greater inflow of employees, but also for a more efficient incorporation of these extra employees into Attica's economic system.

It is finally apparent that the Olympic event fuelled economic development in a scale that makes the assessment of its environmental impact in terms of sustainability a serious need. The next section comes in answer to this requirement.

\section{ENVIRONMENTAL ASPECTS OF THE ATHENS' GAMES}

A project of the magnitude of the Athens' Games, as this was evidenced in economic terms in the previous paragraphs, is expected to have a similar wide-ranging effect on various environmental topics. The analysis performed, adopting the guidelines of the OGGI methodology, indicated a varied range of significance among the various environmental aspects that emerged during the organization and staging phases. The indicators studied regard primarily the Games' context, and

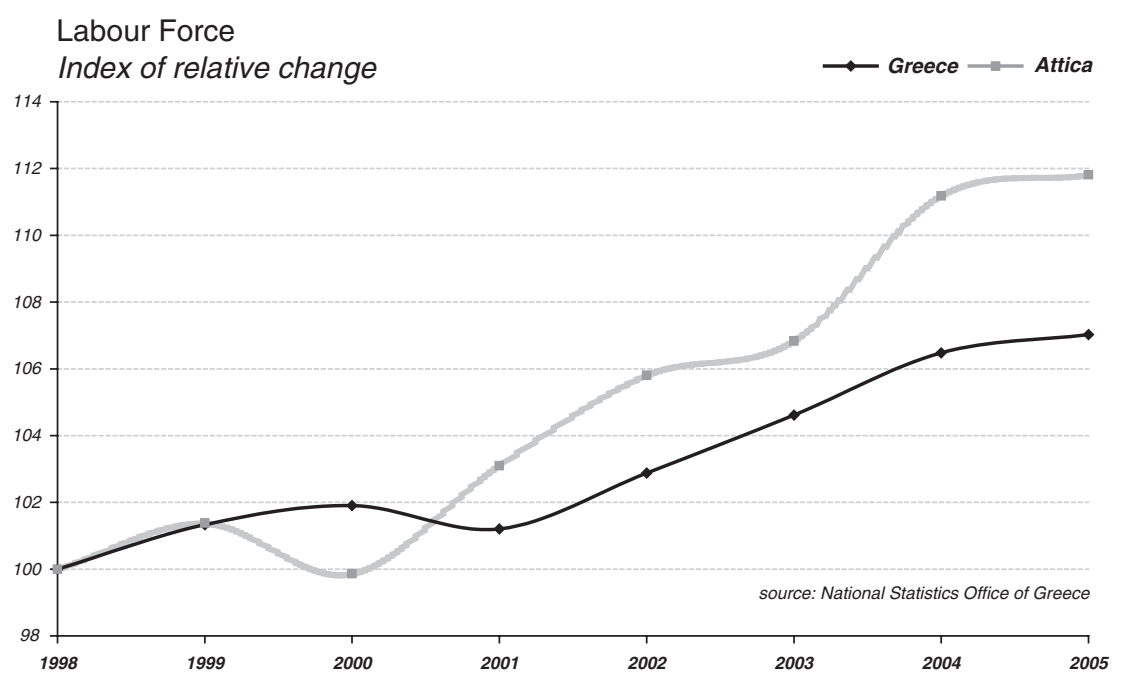

Figure 2: Index of relative change for labour force in Greece and Attica. 


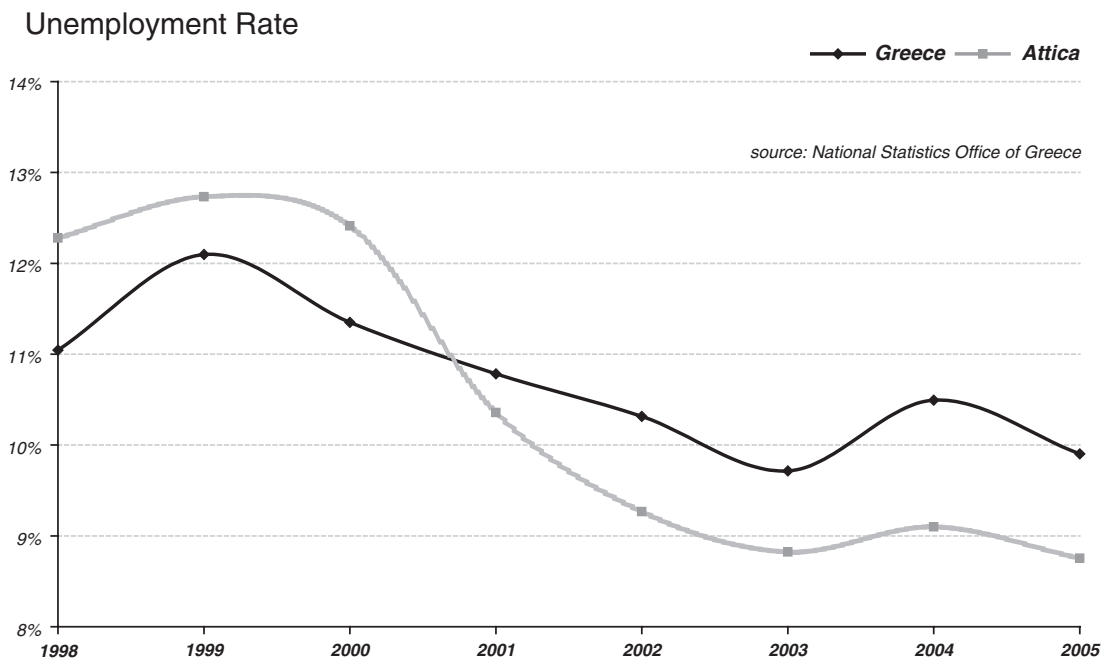

Figure 3: Unemployment rate in Greece and Attica.

they are implemented in a way that their evolution is able to grasp significant changes. These changes could afterwards be assigned to the Games' impact, following some empirical qualitative criteria, such as the relevance of their time of occurrence with the event. The most influential out of these indicators are presented afterwards, while clustered appropriately into sets that portray the Games' generic sustainability impact.

\subsection{Energy consumption}

Energy consumption is intrinsically related to economy, next to the environment itself. This very relationship has been studied in various frameworks to detect causality between energy consumption and economic growth and, although the literature does not converge to a broadly consistent result, the existence of the relationship itself is certain [19]. In Greece, previous studies prove that these variables are bound together by common trends; at least this was the fact until 1996 [20]. This result, along with the proved footprint of economic development, further highlights the essence of monitoring the energy consumption trends.

Under OGGI's prism, energy consumption should be broken down by use and source. The total gross inland consumption increased at a nearly steady annual rate of $2.2 \%$ during the study period from 1996 to 2005. Figure 4 presents the breakdown of this trend, in terms of users. The data indicate that the total increase was a product of consumption from households' users and services, which increased their share in gross consumption from $23.3 \%$ to $26.7 \%$ and from $12.2 \%$ to $14.5 \%$ respectively, while industrial users' share shrunk from $25.6 \%$ to $18.5 \%$. This last trend could serve as an indicator of improved environmental awareness of the Greek industry or a further proof of its shrinkage or both.

The breakdown of energy consumption by source is monitored in Fig. 5. The mix of fossil and renewable sources slightly changed, in favour of fossil fuels. The amount of energy consumed that was produced by renewable sources grew from 57.5 to 64.5 petajoules $(\mathrm{PJ})$ of net calorific value. However, this rate of increase was lower than the total, therefore the renewable share actually 


\section{Energy Consumption by Use}

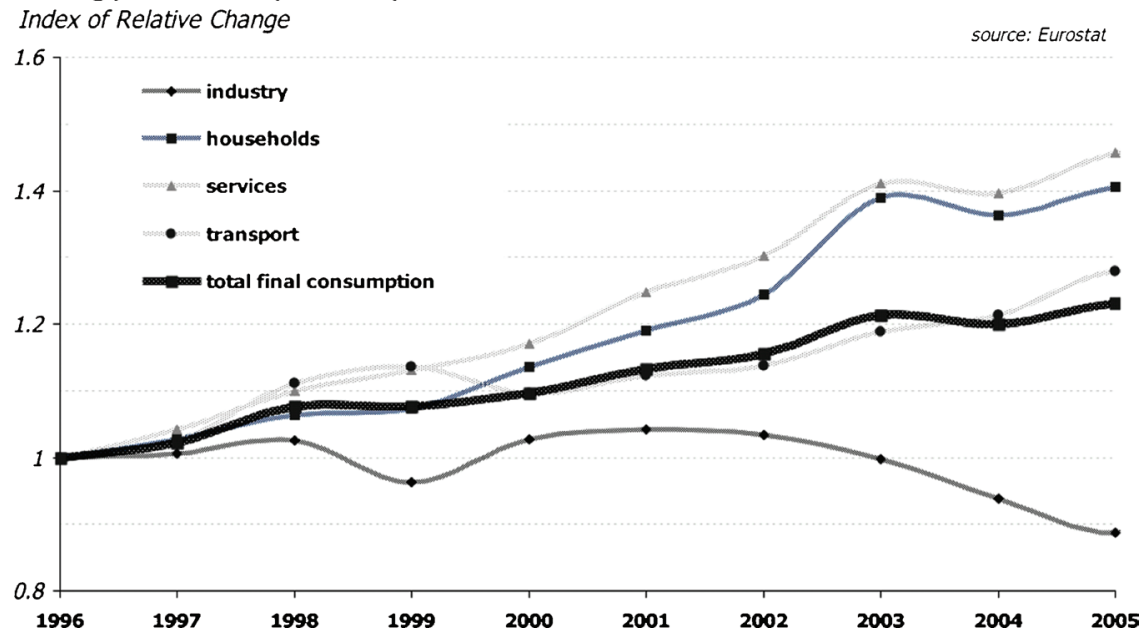

Figure 4: Energy consumption by use in Greece.

\section{Energy Consumption by Source}

Index of relative change

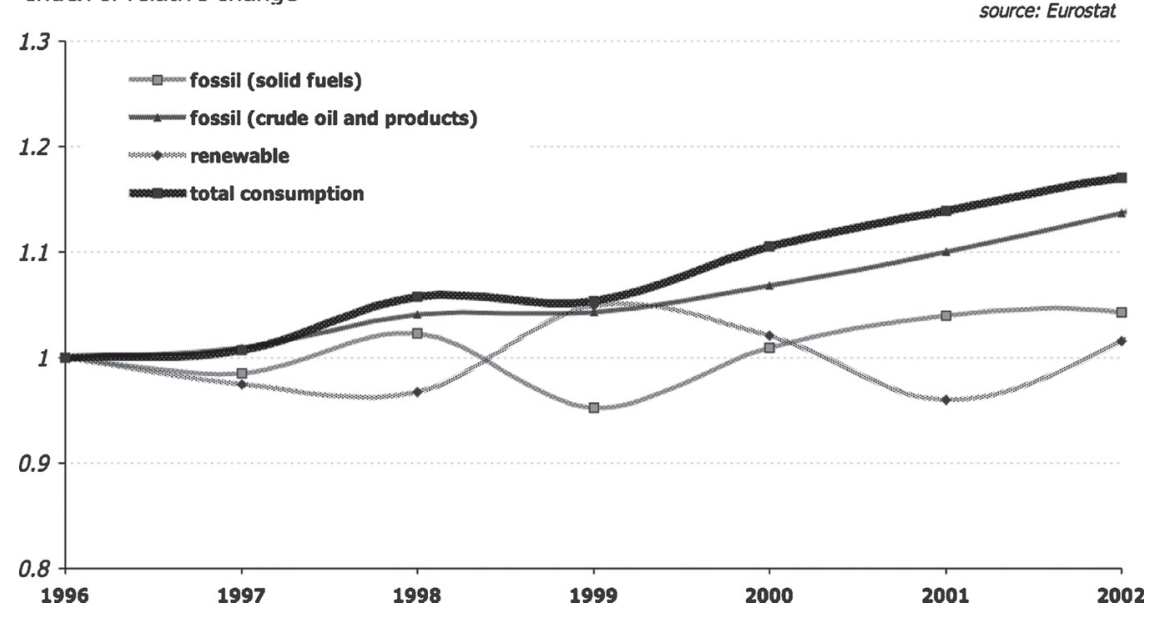

Figure 5: Energy consumption by source in Greece.

decreased from $5.4 \%$ to $5.0 \%$. On the contrary, the increased energy needs were mainly covered from crude oil and petroleum products. The energy consumption from this fossil source climbed from 624 to 748 PJ of net calorific value, namely an increase of $21.7 \%$.

The correlation between the above trends and the Games seems to be vague; any attempt to extract a causal relationship could be dubious. However, the common trends among economic growth and energy consumption are validated; the study of environmental indicators that follows is therefore of great interest. 


\subsection{Transport networks}

During the organization phase of the Games, a substantial recreation of the public transport networks was carried out in the city of Athens. At the beginning of this ambitious program in 1996, an obsolete metro was the only railway system in the Attica region, while the use of buses or private cars was almost unaffordable, as the average duration of stationary traffic was 6 hours per day. After all the often belated and repeatedly over budgeted works, a rather new Athens public transport system, described right below, was ready for serving both the Games and the citizens of Athens.

The basic component of this system is the brand new underground railway that connects more than 20 municipalities of Attica; the operational distance of both the underground and suburban railways is currently greater than $160 \mathrm{~km}$ and it is planned to exceed $250 \mathrm{~km}$, with the construction of new lines which has already begun. The brand new suburban railway is also another essential part of the transport system. The railway links the - also new - Athens International Airport Eleftherios Venizelos with the city's centre and with three other adjacent cities. Its operational distance was extended in 2005 to $120 \mathrm{~km}$. Furthermore, a brand new tram railway was created, which connects the centre with the southern suburbs of Athens and provides a beautiful route nearby the city's coast. In total, as depicted in Fig. 6, the underground railway system has been increased by $174 \%$, while the railway system and bus lanes of more than $90 \mathrm{~km}$ of operational distance had never been implemented before. The reengineering of the public transport system could easily be assigned to the Games' impact, as the event was the motive, as well as the date of completion, for the totality of the relevant works. The improved public transport system is moreover a component of the city's Olympic legacy that testifies the sustainability of the Games, as this arises through the potential extended use of public means of transportation and the subsequent improvement in the quality of life.

Another major impact on the transport networks is as regards the renovation and expansion of the city's road network. The brand new Attiki Odos (means Attica Road) offered $67 \mathrm{~km}$ of motorway through 30 municipalities of Attica Region and serves daily more than 250,000 cars. This motorway has recently been characterized as the safest motorway of Europe due to its lowest accident rates.

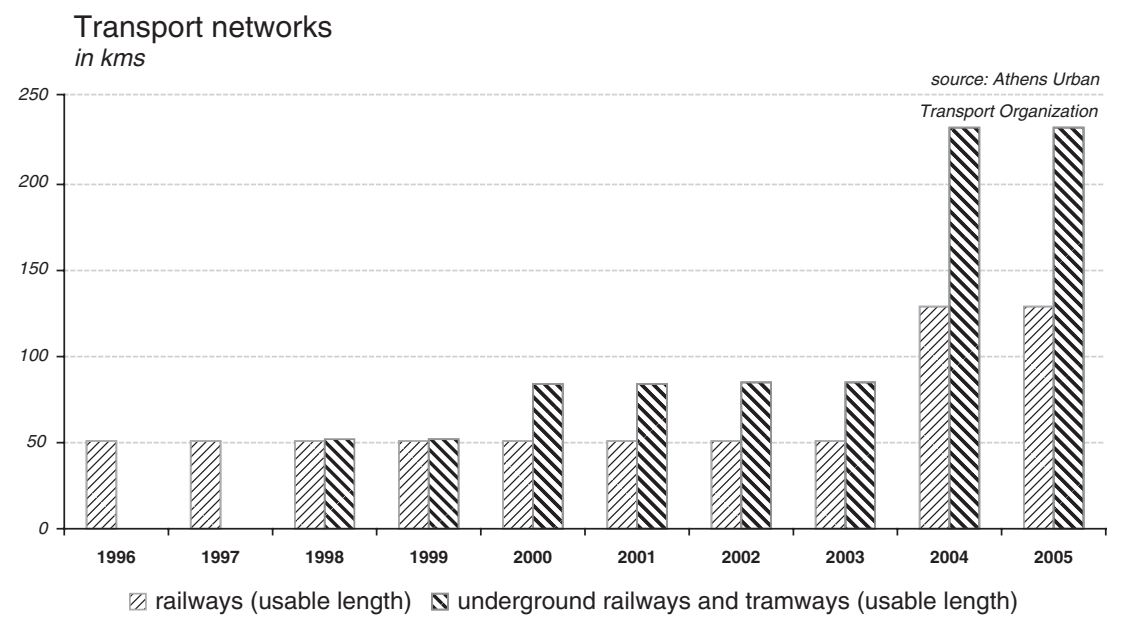

Figure 6: Usable length of transport networks. 
Moreover, almost $130 \mathrm{~km}$ of the existing highway network of the prefecture has been renewed or repaired and more than 100 uneven-underpass complexes accompanied by bridges and tunnels have been added. The improved road-network crosses 50 municipalities of the prefecture and serves almost $100 \%$ of the 5 million of Attica's population. The significance of the new or improved road network could be confirmed by Fig. 7. The operation of Attiki Odos in 2000 resulted in 2 hours less hours of stationary traffic per day on average, a result that further serves the sustainability of the Olympic impact.

\subsection{Pollution}

The question that arises logically from the great improvement in the transport networks concerns primarily the monitoring of effect on life quality, not only in terms of traffic but also in terms of atmospheric pollution. This is analysed in this section. The concentration of various air pollutants is given in a time-series format and is calculated as an annual average in the usual concentration unit, which is micrograms per cubic meter $\left(\mu \mathrm{g} / \mathrm{m}^{3}\right)$. The Greek Ministry of Environment provided all the necessary data for 17 stations of air quality measurement.

The analysed pollutants are $\mathrm{CO}, \mathrm{SO}_{2}, \mathrm{NO}, \mathrm{NO}_{2}, \mathrm{PM} 10$, while time-series graphs are given for a 10 -year period, starting from 1996 to 2005.

\subsubsection{Carbon monoxide (CO)}

$\mathrm{CO}$ is a primary pollutant that is produced whenever non-volumetric combustion occurs within the engines of vehicles. The $\mathrm{CO}$ time-series in Fig. 8 indicates that the pollutant's concentration tends to decrease in the majority of the measurement stations. Since there is clear link between CO concentration and traffic, one can easily infer the positive major impact of the Olympics and the associated road network improvement. However, the introduction and wide use of new engine technologies should also be considered as a major cause for the reduction in $\mathrm{CO}$ concentration.

\section{Average duration of stationary traffic} in hours per day

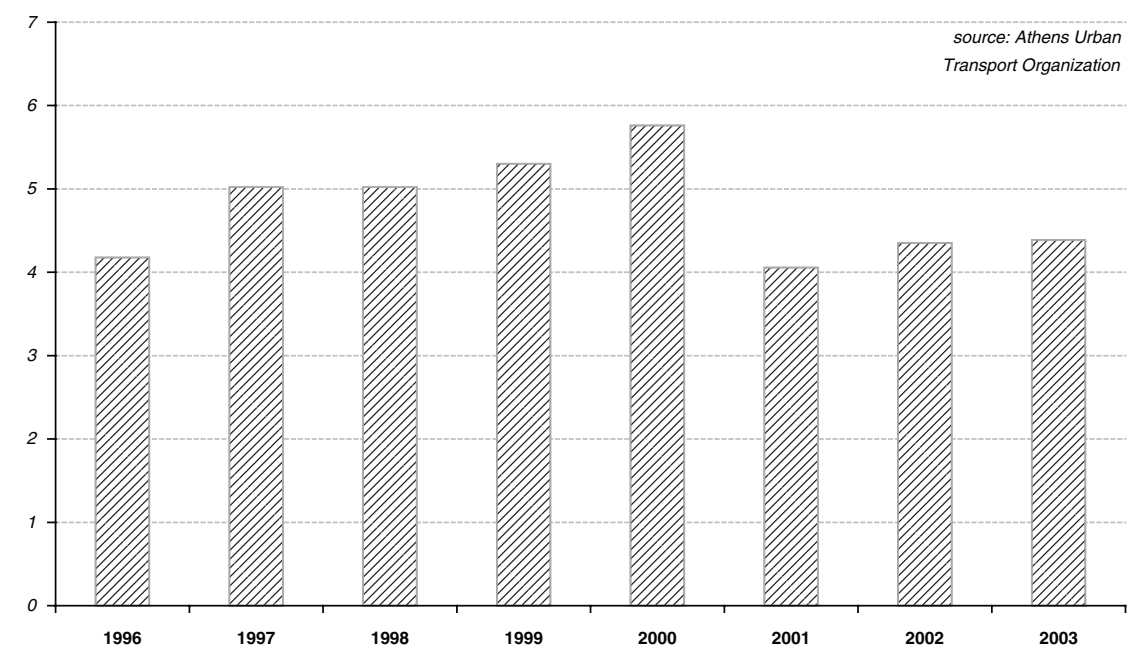

Figure 7: Daily average duration of stationary traffic in the city of Athens. 
Table 1: The 17 stations of air pollutants' concentration measurement.

\begin{tabular}{ll}
\hline Patisiwn & Urban-traffic (UT) \\
Athinas & Urban-traffic (UT) \\
Aristotelous & Urban-traffic (UT) \\
Pireaus 1 & Urban-traffic (UT) \\
Goudi & Urban-traffic (UT) \\
Gewponiki & Suburban-industrial (SI) \\
Liosia & Suburban-background (SB) \\
Lykobrysi & Suburban (S) \\
Marousi & Suburban (S) \\
Nea Smyrni & Urban-background (UB) \\
Pireaus 2 & Urban-background (UB) \\
Peristeri & Urban-background (UB) \\
Galatsi & Urban-background (UB) \\
Elefsina & Suburban-industrial (SI) \\
Zografou & Suburban-background (SB) \\
Thrakomakedones & Suburban-background (SB) \\
Ag. Paraskeyi & Suburban-background (SB)
\end{tabular}

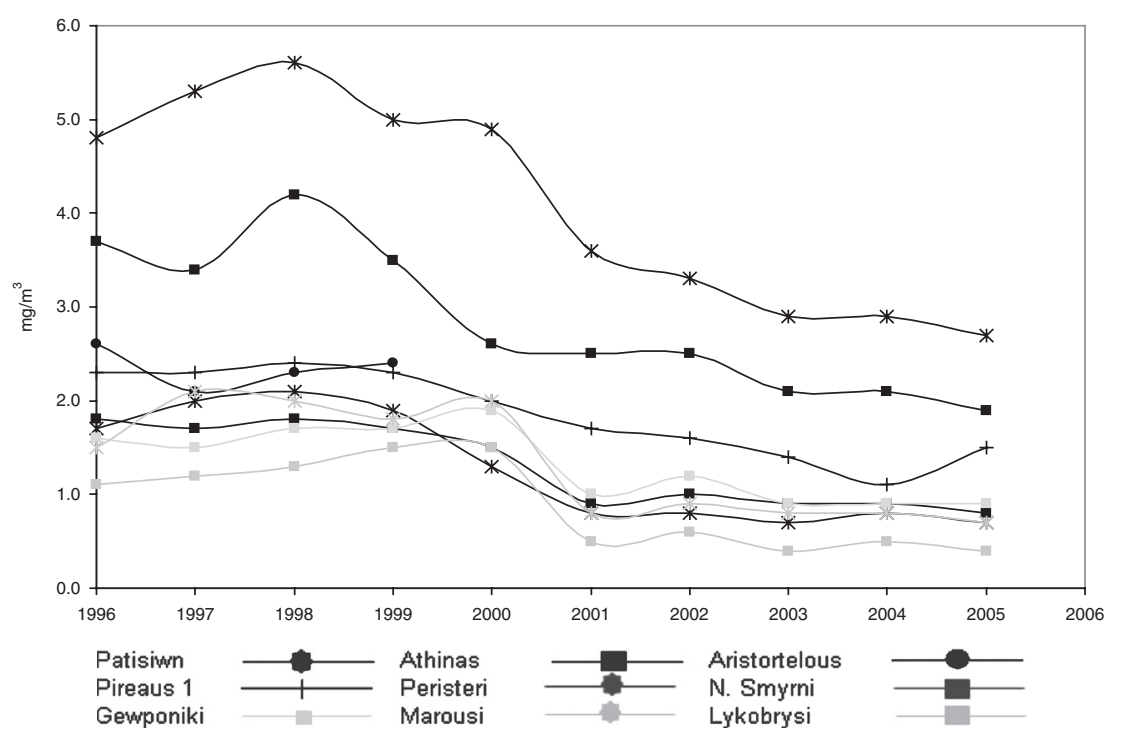

Figure 8: CO time evolution from 1996 to 2005.

4.3.2 Sulphur dioxide $\left(\mathrm{SO}_{2}\right)$

Figure 9 shows the evolution of $\mathrm{SO}_{2}$ concentration with time. In general, a decreasing trend occurs, which is mainly owing to new technology engines, as well as to the improvement of sulphur concentration in gas and oil consumed. However, in most measurement stations, a significant increase is documented during the years 2002 and 2003, which cannot be easily explained. 


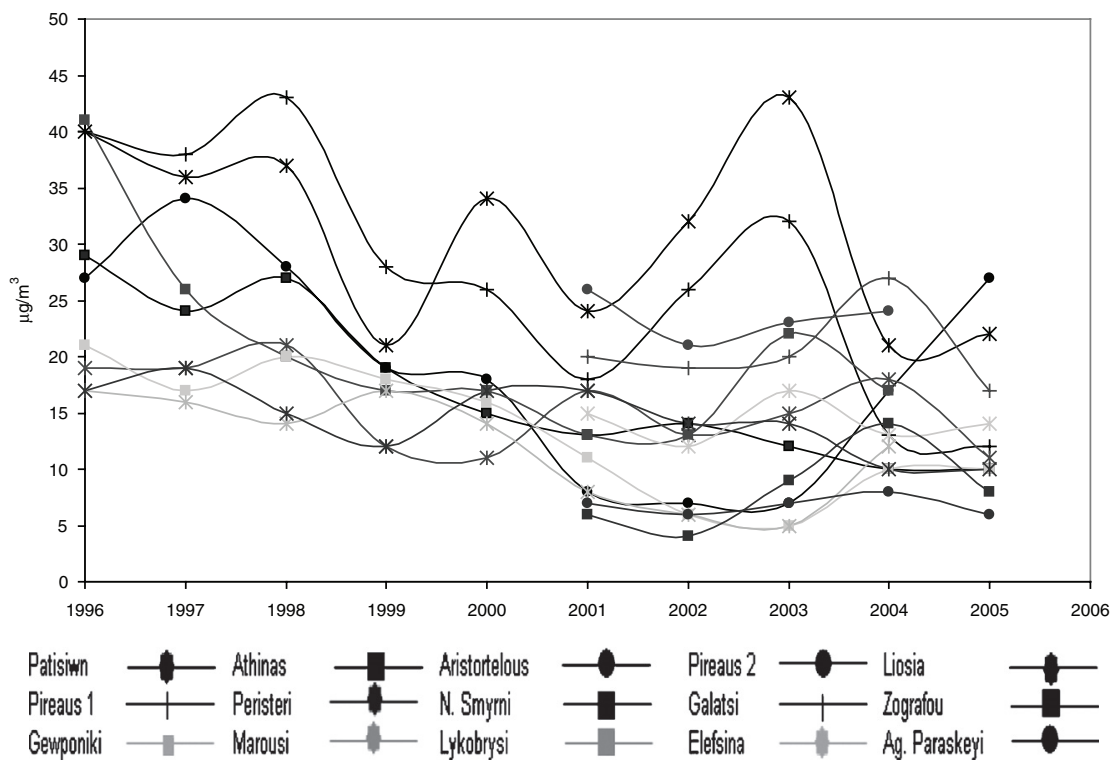

Figure 9: $\mathrm{SO}_{2}$ time evolution from 1996 to 2005.

During the Olympic year 2004, the concentrations seem to turn back again to the previous lower levels.

\subsubsection{Nitrogen dioxide $\left(\mathrm{NO}_{2}\right)$}

$\mathrm{NO}_{2}$ is not a primary pollutant. In other words, its concentration is not depended on emissions and meteorology only, but also on chemical reactions that take place in the atmosphere. For this very reason, the trends emerging from the $\mathrm{NO}_{2}$ graph (Fig. 10) are somehow different from those describing other pollutants. There is a slight decrease in the $\mathrm{NO}_{2}$ concentration till the year 2000, which is more obvious in the measurement in urban stations. Afterwards, the average concentration remains almost constant. In the suburban stations, its levels are lower than the urban stations.

\subsubsection{Nitrogen monoxide (NO)}

The concentration of the primary pollutant NO is slightly decreasing with time, as can be seen in Fig. 11. Higher values are documented, as expected, in the measurements in urban stations. In general, the NO concentration seems to be affected by the Olympic activity: the decreasing trend may be owing to the improvement in the road networks, as well as to the engagement of the new underground and suburban railways. Oscillations in the NO graph could be attributed to occasional atmospheric reactions and cannot be satisfactorily explained.

\subsubsection{Flying parts (PM10)}

In general, the PM10 measurements remain almost constant in all but two stations. These two stations were located very close to Olympic infrastructures and related works. After the end of the Olympic constructions, the concentration of PM10 decreased significantly, compared with the levels in the years 2001-2002, during which the most intense construction activity took place. There were no data for years before 2001 . 


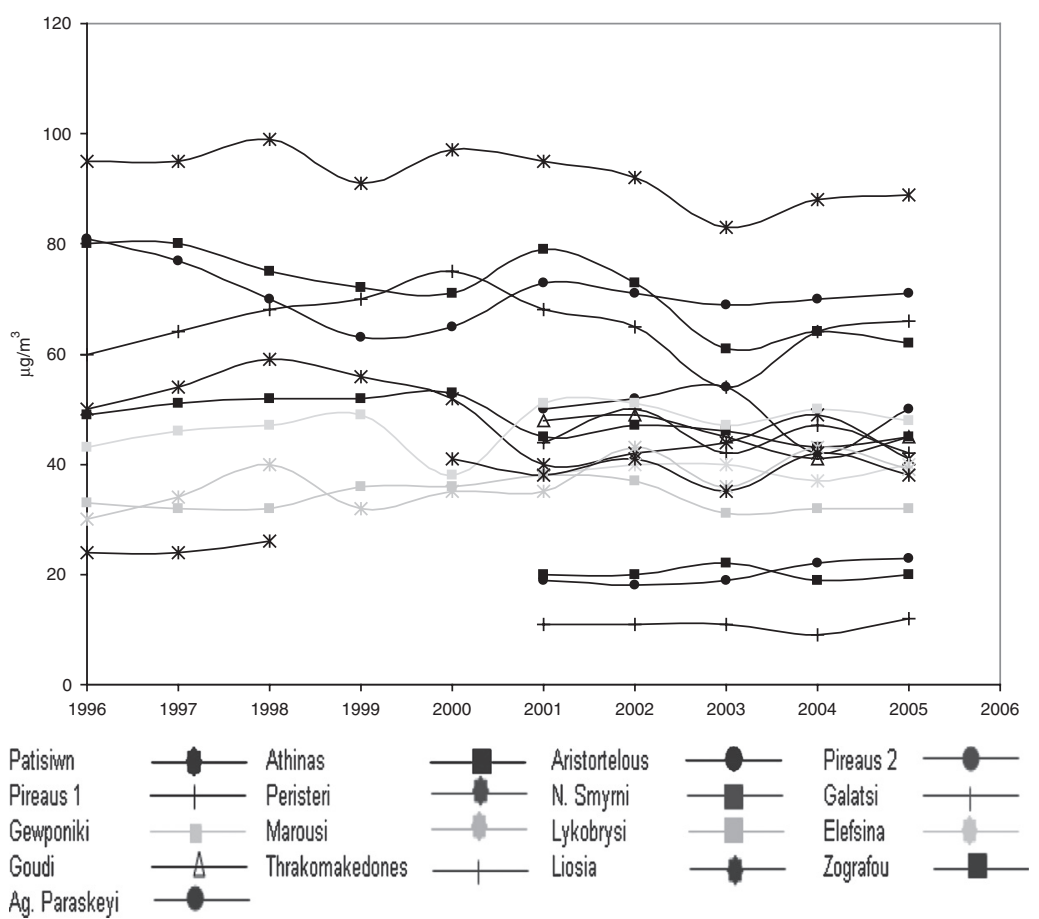

Figure 10: $\mathrm{NO}_{2}$ time evolution from 1996 to 2005.

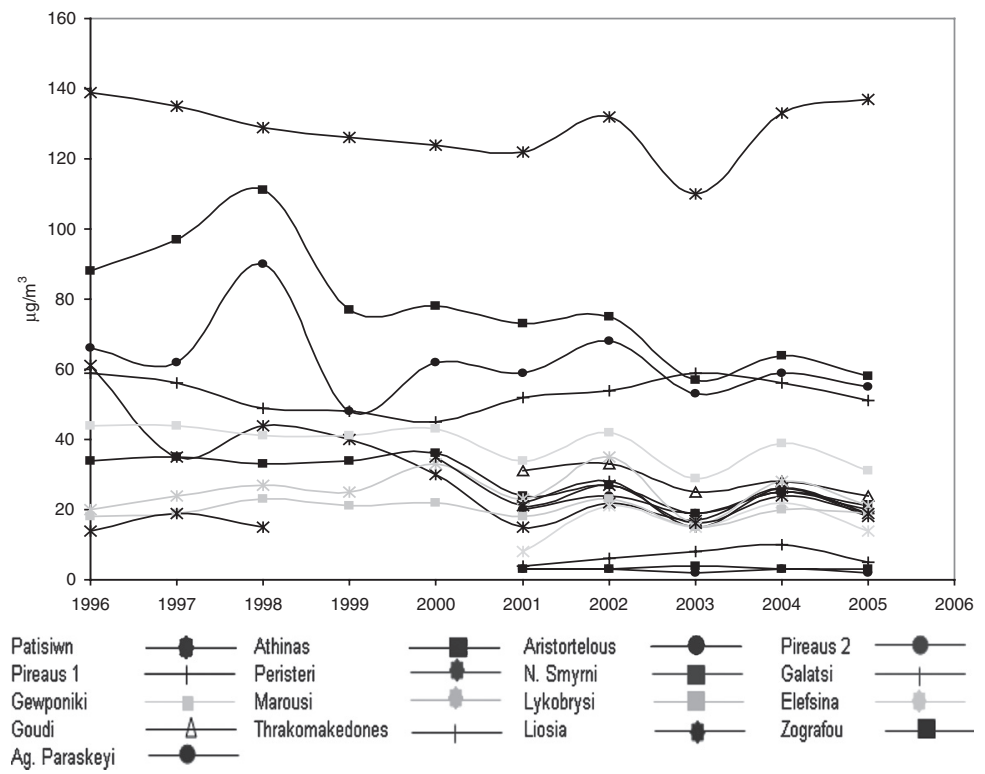

Figure 11: NO time evolution from 1996 to 2005. 


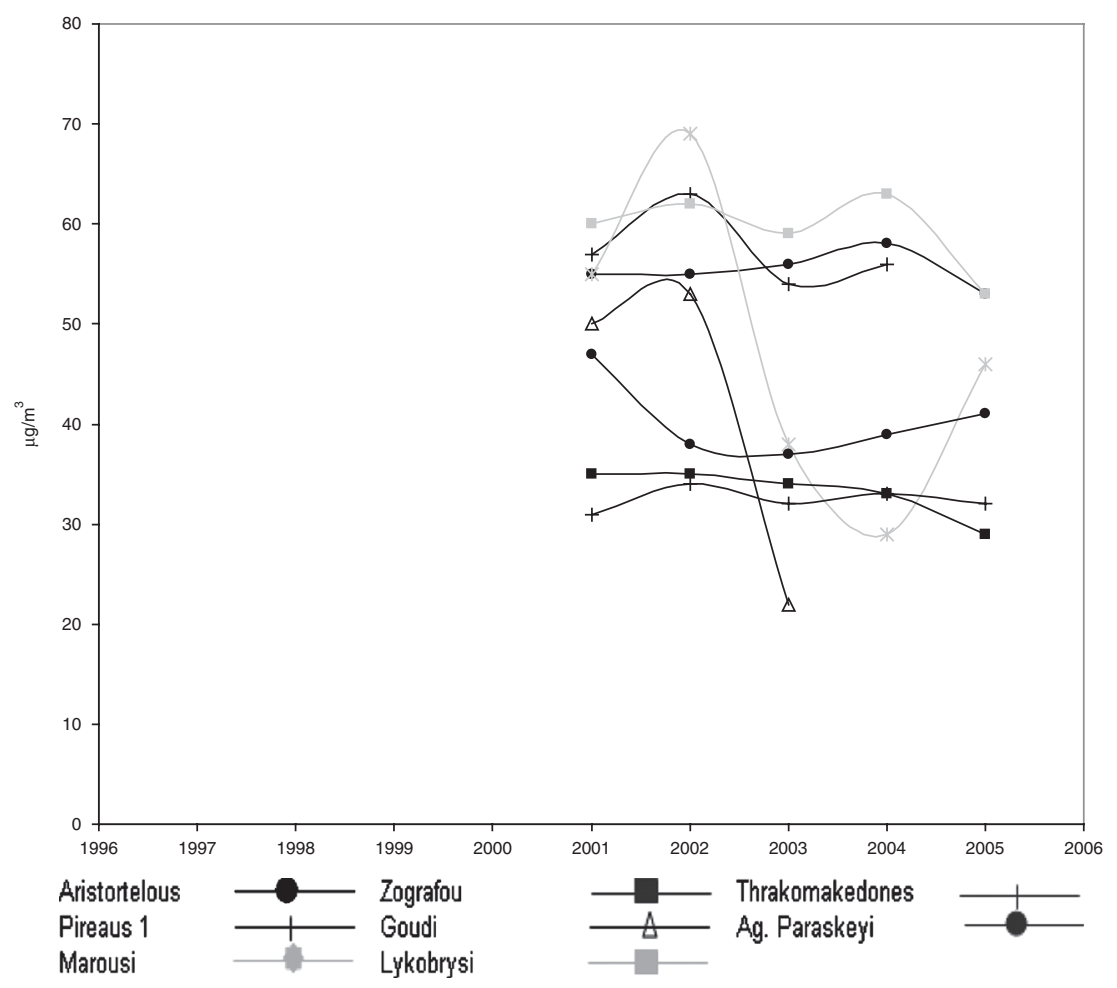

Figure 12: PM10 time evolution from 1996 to 2005.

In general, by the study of the main pollutants concentration throughout the 10-year period 1996-2005, one can extract that the general trend testifies a steady decrease in the capital's pollution indices. This trend was partially interrupted during the period of intense construction works for the Olympic infrastructure, but, after all, the post-Olympic measurements stand as evidence for a less polluted capital and the sustainability of the 2004 Games.

\subsection{Other areas}

The Olympics served moreover as the major or minor cause for improvements in urban planning and development. In the totality of the Olympic cities, including Thessaloniki, Patrai, Volos and Herakleion, a wide revitalization program has been carried out. Especially, Athens has been engaged in a tight urban refurbishment schedule during which ancient sites became easier to access and museums were renewed. The most important out of these works was the restoration of the ancient forum around the Acropolis.

Furthermore, the Games were a reason to increase the number and extent of protected areas and natural sites, in an effort to safeguard the forests and enhance the ecological sensibility and awareness of the population. In the years between 1996 and 2004, the surface of protected areas has been increased by more than $6 \%$, especially in the wider areas of great ecological importance and biodiversity. 


\section{CONCLUSIONS}

The enormous size of the modern Olympics and the controversial relationship between economic growth and environmental protection give rise to the pressing need for testing the compatibility of the Games with the principles and directions of sustainable development. This study is the first attempt to assess the sustainable impact of an Olympic event, implementing the methodology shaped by the IOC, namely the guidelines of the OGGI project. The text addresses the sustainable impact of the Olympic Games of Athens 2004, focusing mainly on economic and environmental aspects. The principal findings could be summarized as follows:

The major part of the total 11.274 billion euro spent on the Olympic project was mainly funded by public subsidies. The impact of the event on the regional economy was significant. During the organization phase, the volume of labour force presented a greater increase in the Attica prefecture than in national scale, while the unemployment rate presented a higher decrease. The Games also resulted in the growth of the sectors of constructions and hotels/restaurants in a scale larger than the overall growth of the national economy.

The sustainable impact of the Games' event in the sphere of the environment was also of great significance. While the Games' impact on energy consumption seemed vague and not clearly traceable, the Games served especially on the issue of transport networks as a strict pressure factor that finally resulted in a massive reengineering of the public transport system and the road network. The underground railway network grew by a factor of 1.74 , a new railway and bus lanes network was constructed and $200 \mathrm{~km}$ of rather new or upgraded motorways resulted in a significant decrease in stationary traffic. The resulting decrease in atmospheric pollutants after the years of intense constructive works, despite the high consumption of raw materials, is a further documentation of the sustainable impact of the Games. In general, the time-series for the concentration of the main atmospheric pollutants, namely $\mathrm{CO}_{2}, \mathrm{CO}, \mathrm{NO}_{2}$ and $\mathrm{SO}_{2}$, were characterized by the common feature of a local maximum around the year 2000. Since then a moderate decrease, below the limits established by the European Union, describes the time evolution of these pollutants. The improvements in the road network, mainly the operation of Attiki Odos, and the opening of extensions to the underground railway that were completed in this period may be responsible for this decrease. In addition, the overall improvement in public transportation and the consequent change in habit of Athens' citizens (to use public transport instead of their cars) may be another significant reason.

It has to be noted, however, that the PM10 pollutant, which corresponds to tiny 'flying' solid microparts, has been increased and presented a peak during the years 2001-2002. After that, the levels seemed to turn back to lower levels. The temporary increase in 2001-2002 can be attributed to the peak phase of public works, especially those related to new roads, as well as sport-facilities and infrastructure. This consideration of the Olympic impact in terms of sustainability is a rather novel but promising research area. The constant growth of the Games' scale, as well as the increased concerns on sustainability, supports this belief. The study could serve as a starting point for the relevant literature and also as a reference for evaluating and comparing events similar in size and nature. The assessment could be extended to the areas of tourism or social impact and the modification of the framework for its use in a more rigid but practicable setting are directions in which further research could be focused.

\section{ACKNOWLEDGEMENTS}

The authors wish to make special reference to Professor Dr Maria Tombrou and Dr Elisabeth Bossioli from the National Kapodistrian University of Athens, Department of Atmospheric Physics, for providing data regarding air pollution in Athens and the associated time-series graphs. 


\section{REFERENCES}

[1] Lucas, R.E., On the mechanics of economic development. Journal of Monetary Economics, 22, pp. 3-42, 1988.

[2] Georgescu-Roegen, N., The Entropy Law and the Economic Process, Harvard University Press: Cambridge, 1971.

[3] Meadows, D.H., Meadows, D.L., Randers, J. \& Behrens, W.W., The Limits to Growth, Earth Island Limited: London, 1972.

[4] Panayotou, T., Economic growth and the environment, CID Working Paper No. 56, Harvard University, 2000.

[5] Beckerman, W., Economic growth and the environment: whose growth? Whose environment? World Development, 20, pp. 481-496, 1992.

[6] Grossman, G. \& Kreuger, A., Economic growth and the environment. Quarterly Journal of Economics, 110(2), pp. 353-377, 1995.

[7] Selden, T.M. \& Song, D., Environmental quality and development: is there a Kuznets curve for air pollution emissions? Journal of Environmental Economics and Management, 27, pp. 147-162, 1994.

[8] World Commission on Environment and Development (WCED), Our Common Future: The Brundtland Report, Oxford University Press: Oxford, 1987.

[9] United Nations, Agenda 21. United Nations Conference on Environment \& Development, Rio de Janerio, Brazil, 1992.

[10] Bossel, H., Indicators for Sustainable Development: Theory, Method, Applications, International Institute for Sustainable Development Report, Manitoba, Canada, 1999.

[11] United Nations Commission on Sustainable Development, Indicators of Sustainable Development, Guidelines and Methodologies, Third session report, 1995.

[12] Preuss, H., The Economics of Staging the Olympics, Edward Elgar Publishing: UK, 2004.

[13] Arthur Andersen, Economic Impact Study of the Sydney 2000 Olympic Games, Executive Summary, 1999.

[14] Greenpeace, How Green Are the Games, Sydney, Australia, 2000.

[15] Griethuysen, P., A general framework for the identification of the global impact of major sports events. Proceedings of the SEMOS, Lausanne, pp. 97-103, 2001.

[16] Hug, P.A., Sports event assessment. Proceedings of the SEMOS, Lausanne, pp. 104-109, 2001.

[17] Griethuysen, P. \& Hug, P.A., Project OGGI Olympic Games Global Impact. Cadre d'analyse pour l'identification de l'impact global des Jeux Olympiques, Lausanne, 2001.

[18] Griethuysen, P. \& Hug, P.A., Project OGGI Olympic Games Global Impact. Fiches techniques, Lausanne, 2001.

[19] Masih, A. \& Masih, R., Energy consumption, real income and temporal causality: results from a multi-country study based on cointegration and error-correction modelling techniques. Energy Economics, 18, pp. 165-183, 1996.

[20] Hondroyiannis, G., Lolos, S. \& Papapetrou, E., Energy consumption and economic growth: assessing the evidence in Greece. Energy Economics, 24, pp. 319-336, 2002.

This paper is an extended version of the one presented by the authors at the 1st International Conference on Environmental Economics and Investment Assessment, held on the island of Mykonos in 2006, Volume 98, WIT Transactions on Ecology and the Environment (ISBN: 1-84564-046-2/Online ISSN: 1743-3541). Edited by K. Aravossis, C.A. Brebbia, E. Kakaras and A.G. Kungolos. 